\title{
MOVIE REVIEW SENTIMEN ANALISIS DENGAN METODE NAÏVE BAYES BASE ON FEATURE SELECTION
}

\author{
Andilala $^{1}$ \\ ${ }^{1}$ Program Studi Teknik Informatika, Fakultas Teknik \\ Universitas Muhammadiyah Bengkulu \\ 1ªndilalaumb@gmail.com
}

\begin{abstract}
Abstrak: Perkembangan internet dewasa ini berkembang sangat pesat yang secara tidak langsung mendorong penciptaan konten web pribadi yang melibatkan sentimen seperti blog, tweets, web forum dan jenis-jenis media sosial. Manusia sering kali mengambil keputusan yang didasari oleh masukan dari teman, saudara, kolega dan lain-lain. Dengan didukung ketersediaan pertumbuhan dan popularitas sumber daya yang kaya akan pendapat seperti review situs online dan blog pribadi Misalnya, pengungkapan perasaan pribadi yang memungkinkan pengguna untuk membahas masalah seharihari, bertukar pandangan politik, mengevaluasi layanan dan produk. Pada penelitian ini diterapkan metode opinion mining dengan menggunakan algoritma Nä̈ve Bayes berbasis Feature Selection. Penggujian metode ini menggunakan dataset Movie Review yang di download dari situs http://www.cs.cornell.edu/People/pabo/movie-review-data/. Data tersebut awalnya dikumpulkan dari $I M D b$ (Internet Movie Database). Tujuan dari penelitian ini adalah untuk meningkatkan akurasi dari algoritma Nä̈ve Bayes dalam mengklasifikasikan dokumen. Akurasi yang dicapai dalam penelitian ini adalah sebesar 95,70\% melampaui akurasi yang dijadikan base line dalam penelitian ini adalah sebesar $94,85 \%$.
\end{abstract}

Kata Kunci : Naïve Bayes, Selection Feature, Opinion mining, Information Gain, Sentiment Analysis.

Abstract: The development of internet today is growing very fast which indirectly encourage the creation of personalized web content that involves sentiments such as blogs, tweets, web forums and other types of social media. Humans often make decisions based on input from friends, relatives, colleagues and others, with the support of growth and popularity of the availability of resources such opinion online review sites and personal blogs, for example, disclosure of the personal feelings that allow users to discuss everyday problems, exchanging political views, evaluate services and products. In this research, opinion mining methods are applied using the Naive Bayes algorithm-based Feature Selection. These methods use the dataset Movie Review http://www.cs.cornell.edu/People/pabo/mo vie-review-data/ downloaded from the site. The data was originally collected from the IMDb (Internet Movie Database). The purpose of this study was to improve the accuracy of the Naive Bayes algorithm in classifying documents. accuracy is achieved in this study amounted to
95.70\% accuracy which exceeds the base line made in this study amounted to $94.85 \%$.

Keywords: Nä̈ve Bayes, Selection Feature, Opinion mining, Information Gain, Sentiment analysis.

\section{PEndahuluan}

Perkembangan internet dewasa ini berkembang sangat pesat dengan ditandai meningkatnya pengguna internet dunia. Kemajuan dari Web 2.0 mendorong penciptaan konten web pribadi yang melibatkan sentimen seperti blog, tweets, web forum dan jenis-jenis media sosial. Dengan adanya keragaman aplikasi yang tumbuh di internet sebagian orang atau suatu badan dapat mengambil keuntungan dengan memanfaatkan pendekatan opinion mining, misalnya kampanye pemasaran dapat 
menerima dan mengevaluasi umpan balik dari basis pengguna yang besar, politisi dapat memperkirakan popularitas mereka, produsen dapat mengidentifikasi kelemahan dari produk mereka, pemerintah dapat meningkatkan kualitas layanan informasi yang ditawarkan kepada masyarakat sehingga pemerintah lebih bertanggungjawab kepada masyarakatnya dan dapat memajukan transparansi di sektor publik [1]. Salah satu tujuan dari opinion mining dan sentiment analysis adalah untuk membantu orang menemukan informasi yang berharga dari sejumlah data yang tidak terstruktur [2].

Sentiment Analysis atau Opinion Mining baru-baru ini menjadi topik menarik yang mencoba untuk menggabungkan statistik, kecerdasan buatan dan teknologi. Data Mining dalam kerangka terpadu [3] opinion mining adalah informasi tekstual yang berada di dalam web dan berisi tentang fakta dan opini. Opini merupakan pernyataan subjektif yang mencerminkan persepsi seseorang terhadap sesuatu peristiwa, misalnya tentang opini-opini yang berkembang seperti krisis di Libya dan Suriah, perdebatan tentang krisis ekonomi di Yunani, dan downdrating atas kredibilitas Amerika Serikat adalah beberapa topik kontroversial yang dimuat dalam berita sehari-hari. Menganalisa rating movie untuk mengetahui tingkat pendapatan dari pemutaran suatu movie [4]. Dan review movie juga dapat dimanfaatkan atau digunakan oleh penikmat film untuk memutuskan film apa yang mau ditonton dan para produser film dapat memanfaatkan opini tersebut untuk mengetahui penilaian yang diberikan oleh para penikmat film tentang filmfilm yang paling banyak dikritik.

Ada banyak metode yang telah digunakan dalam bidang opinion mining dan sentiment analysis diantaranya adalah Naive Bayes (NB) dan Support Vector Machine (SVM), masing-masing metode tersebut mempunyai kelebihan dan kekurangan masing-masing. Misalnya SVM yang memiliki accuracy cukup tinggi dalam pengklasifikasian dokumen seperti penelitian [1] [5] [6] [7] [8], tetapi SVM memiliki kelemahan yaitu dari segi kinerja dan kecepatan komputasi yang lambat [9]. Sedangkan NB memiliki akurasi paling rendah dalam pengklasifikasian dokumen seperti accuracy yang di hasilkan dalam peneltian [1] [4] [6], tetapi kelebihan NB dari metode yang lain khususnya dari SVM adalah $N B$ cukup mudah digunakan dan memiliki accuracy yang lebih baik jika menggunakan dataset yang besar [9] [10].

Dalam penelitiannya [6] mengatakan bahwa abasi et al dan $A u$ gamon menyarankan untuk menambahkan langkah seleksi fitur untuk proses Machine Learning jika ingin meningkatkan kinerja dari klasifikasi. Seleksi fitur atau pemilihan atribut dapat dilakukan berdasarkan perhitungan bobot yang diperoleh. Dalam penelitian ini, seleksi fitur yang digunakan adalah Information Gain (IG) yang mengacu ke penelitian [11] [12] berdasarkan skor fitur yang merupakan kualitas istilah dalam dataset dokumen. Sebuah istilah dengan nilai tinggi berarti penting atau relevan dengan dataset. Maka tujuan dari penelitian ini adalah untuk memperbaiki keakuratan metode Naive Bayes dalam mengklasifikasikan dokumen dengan pemilihan fitur merujuk ke penelitian [7] [6] [11] [12] [13]. Dan penelitian ini nantinya dapat dimanfaatkan untuk mengetahui tingkat sentiment yang ada di forum web seperti : politisi dapat memanfaatkannya untuk mengetahui popularitas mereka, produsen suatu produk dapat memanfaatkannya untuk mengetahui opini-opini 
yang ada tentang produk mereka.

\section{TINJAUAN PUSTAKA}

\section{A. Penelitian Terkait}

Bo Pang et al [4] melakukan penelitian untuk mengetahui rating sebuah movie dengan cara melihat dan mengklasifikasikan rating ke label positif atau negatif dari sebuah movie, dataset yang digunakan dari Internet Movie Database (IMDb), memanfaatkan metode klasifikasi machine learning Naïve Bayes Clasifier (NBC), Maksimum Entropi (ME) dan Support Vector Machine (SVM) dan menggunakan pemilihan fitur unigram, n-gram dan POS. Hasil dari penelitian tersebut dinyatakan bahwa algoritma terbaik dan efektif untuk klasifikasi tebaik adalah SVM, sedangkan NBC adalah klasifikasi terburuk.

Penelitian Jingnian et al [14] mereka melakukan penelitian dengan menkomparasi beberapa metode feature selection seperti information gain (IG), Multi-class Odds Ratio (MOR) dan Class Discriminating Measure (CDM), Extended Odds Ratio (EOR) dan Weighted Odds Ratio (WOR) dan MC-OR menggunakan multikelas dataset yaitu dataset routers dan dataset berbahasa Cina. Accuracy tertinggi yang mereka dapatkan adalah dengan pemilihan feature $C M D$ dan $M O R$ dengan accuracy sebesar $85,60 \%$

Selanjutnya penelitian Somayajulu et al [7] mereka melakukan penelitian tentang review movie dengan menggunakan dataset dari $I M D b$ dan menggunakan empat metode klasifikasi yaitu, Naïve Bayes (NB), Support vector Machine (SVM), Complemented Naïve Bayes (CNB) dan Discriminative Partitioning using Bayesian Networks (DPBN) dengan pemilihan fitur Information Gain (IG).
Selanjutnya abasi et al [5] mereka melakukan penelitian tentang klasifikasi sentiment berbagai bahasa dengan menggunakan pendekatan SVM dan pemilihan fitur Entropy Weighted Genetic Algorithm (EWGA), Information Gain (IG) dan Genetic Algorithm (GA), mereka mengembangkan feature selectiom EWGA dengan memanfaatkan informasi yang dihasilkan dari IG. Dataset untuk klasifikasi yang mereka gunakan adalah bahasa inggris dan bahasa Arab. Accuracy tertinggi yang mereka dapatkan adalah sebesar 95,55\% untuk EWGA.

B. Landasan teori

a. Text Mining

Text mining adalah salah satu bidang khusus dari data mining [15], text mining dapat didefinisikan sebagai suatu proses menggali informasi dimana seorang user berinteraksi dengan sekumpulan dokumen menggunakan tools analisis yang merupakan komponenkomponen dalam data mining yang salah satunya adalah kategorisasi. Tujuan dari text mining adalah untuk mendapatkan informasi yang berguna dari sekumpulan dokumen. Jadi, sumber data yang digunakan pada text mining adalah kumpulan teks yang memiliki format yang tidak terstruktur atau minimal semi terstruktur. Permasalahan yang dihadapi pada text mining sama dengan permasalahan yang terdapat pada data mining, yaitu jumlah data yang besar, dimensi data yang tinggi dan struktur yang terus berubah, dan data noise.

\section{b. Opinion Mining}

Dalam bukunya Bo pang [3] mengatakan bahwa opinion mining dan sentiment analysis adalah menunjukkan bidang studi yang sama (daerah sub analysis subjektif) yang bertujuan 
untuk mengetahui sebuah opini termasuk positif atau negatif Ada dua cara untuk melakukan atau opinion mining yaitu machine learning dan Semantic orientation [2]. Machine learning dilakukan dengan cara mengumpulkan dan menyeleksi opini yang ada di web, selanjutnya opini-opini tersebut di berikan label positif dan negatif, sedangkan semantic orientation merupakan kebalikan dari machine learning dan digunakan secara real time.

\section{c. Movie Review}

Review movie memiliki karakteristik yang unik. Ketika seseorang menulis review film, ia mungkin berkomentar beberapa elemen dari sebuah film (screen-play, vision effect, music) dan ada juga dengan orang-orang yang terlibat di dalam film (sutradara, penulis skenario, aktor).

\section{d. Information Gain}

Feature adalah seluruh kata yang muncul dalam training set. Set ini biasanya sangat besar yaitu satu dimensi untuk setiap kata unik sehingga memiliki feature space yang sangat besar. Feature selection adalah metode untuk mereduksi dimensi feature space dengan cara memilih kata-kata yang paling informative. Salah satu metode yang terbukti sangat efektif dalam melakukan feature selection adalah Information Gain (IG), Metode IG berfungsi menghitung jumlah bit informasi yang dihasilkan dengan jalan mengamati kemunculan sebuah kata dalam dokumen. Sebuah kata akan memiliki nilai $I G$ yang tinggi jika kata tersebut muncul di banyak dokumen dalam suatu kelas tertentu.

Tujuan penerapan IG adalah informasi atribut atau fitur diukur dengan kemurnian. Ini merupakan jumlah informasi bahwa fitur ini membawa dan membantu dalam mengklasifikasikan contoh baru berdasarkan kata ini saja. Persamaan Information Gain [25] seperti di bawah ini :

$$
\begin{aligned}
& \text { Infogain }=\quad \sum_{j=1}^{k} p(C j) \log P(C j)+P(W) \\
& \sum_{j=1}^{k} p(C j / W) \log P(C j / W)+\mathrm{P}(\bar{W}) \quad \sum_{j=1}^{k} p(C j / \\
& (\bar{W}) \log P(C j /(\bar{W}))
\end{aligned}
$$

Dimana $P(c j)$ adalah rasio jumlah kategori dokumen $C j$ untuk jumlah pelatihan seluruh dokumen, $P(w)$ adalah rasio jumlah dokumen yang mencakup term $W$ untuk jumlah semua dokumen pelatihan, $P(C j \mid W)$ adalah rasio jumlah dokumen yang meliputi term $\mathrm{w}$ yang merupakan milik category $C j$ untuk jumlah dokumen yang meliputi term $W$ disemua sampel pelatihan, $P(w \overline{)}$

adalah jumlah rasio dari jumlah dokumen yang tidak termasuk term $W$ untuk jumlah semua dokumen pelatihan, $P\left(C_{j} \mid w^{-}\right)$adalah rasio dokumen yang tidak termasuk term w tetapi milik kategori $C j$ untuk jumlah dokumen yang tidak termasuk term dalam semua sampel pelatihan.

\section{e. TFIDF}

Metode pembobotan adalah dimana tiap kata atau simbol dihitung sebagai satu fitur. Adapun perhitungan bobot digunakan adalah Term Frequency-Inverse Document Frequency (TFIDF).

Bobot TFIDF adalah statistik numerik yang mencerminkan betapa pentingnya sebuah kata dalam suatu dokumen dalam koleksi atau corpus. Hal ini sering digunakan sebagai faktor bobot dalam pencarian informasi dan pertambangan teks. Nilai tf-idf meningkat secara proporsional dengan berapa kali suatu kata muncul dalam dokumen, tetapi diimbangi dengan frekuensi dari kata dalam corpus, yang membantu untuk mengendalikan fakta bahwa beberapa kata 
umumnya lebih umum dibanding yang lain. Salah satu fungsi peringkat paling sederhana dihitung dengan menjumlahkan tf * IDF sebagai mana ditunjukkn dengan persamaan dibawah ini :

$$
w i j=t f_{i j} \times(\log (D / d f j)+1) \ldots
$$

dimana $t f_{i j}$ adalah jumlah kemunculan term pada kategori $W_{i j}$, dan $D$ adalah jumlah dokumen yang dijadikan training, $d f j$ adalah probabilitas kemunculan term pada kategori $W$.

\section{f. Nä̈ve Bayes}

Algoritma mesin pembelajaran memainkan peran penting dalam melatih sistem dengan kategori yang telah ditetapkan di antaranya Naïve Bayes yang memiliki beberapa fakta menarik, mudah diterapkan dan memiliki akurasi yang lebih baik di dataset besar [10]. Pada NBC setiap record direpresentasikan dalam pasangan atribut $<a 1, a 2, \ldots$, an $>$ dimana $a_{1}$ adalah kata pertama, a2 adalah kata kedua dan seterusnya.

Sedangkan V adalah himpunan kategori dokumen. klasifikasi, pendekatan Bayes akan menghasilkan label kategori yang paling tinggi probabilitasnya $\left(V_{M A P}\right)$ dengan masukan atribut < $a_{1}, a_{2}, \ldots, a_{n}>V_{M A P}=\arg _{v j \epsilon} V \max P\left(v j \mid a_{1}, a_{2}, \ldots, a_{n}\right.$ ) ...(2)

Teorema Bayes menyatakan :

$P(B \mid A)=\frac{P(A \mid B) P(B)}{P(A)}$

Menggunakan teorema Bayes ini, persamaan (16) ini dapat ditulis :

$$
\mathrm{V}_{\mathrm{MAP}}=\arg _{\mathrm{vj \varepsilon v}} \max \frac{P(a 1, a 2, \ldots a n \mid v j) P(v j)}{P(a 1, a 2, \ldots a n)}
$$

$P\left(\mathrm{a}_{1}, \mathrm{a}_{2}, \ldots, \mathrm{a}_{\mathrm{n}}\right)$ nilainya konstan untuk semua $\mathrm{v}_{\mathrm{j}}$ sehingga persamaan ini dapat ditulis sebagai berikut :

$\mathrm{V}_{\mathrm{MAP}}=\arg _{\mathrm{v} j \varepsilon \mathrm{v}} \max P\left(\mathrm{a}_{1}, \mathrm{a}_{2}, \ldots, \mathrm{a}_{\mathrm{n}} \mid \mathrm{v}_{\mathrm{j}}\right) P\left(\mathrm{v}_{\mathrm{j}}\right)$

Tingkat kesulitan menghitung $P\left(\mathrm{a}_{1}, \mathrm{a}_{2}, \ldots\right.$, an $\left.\mid \mathrm{v}_{\mathrm{j}}\right)$ menjadi tinggi karena jumlah term $P\left(\mathrm{a}_{1}, \mathrm{a}_{2}, \ldots, \mathrm{a}_{\mathrm{n}} \mid\right.$ $\mathrm{v}_{\mathrm{j}}$ ) bisa jadi akan sangat besar. Ini disebabkan jumlah term tersebut sama dengan jumlah kombinasi posisi kata dikali dengan jumlah kategori. Nä̈ve Bayes Classifier menyederhanakan hal ini dengan mengasumsikan bahwa dalam setiap kategori, setiap kata independen satu sama lain. Dengan kata lain : $P\left(a_{1}, a_{2}, \ldots\right.$ $\left.a_{n} \mid v_{j}\right)=\prod_{i} P\left(a_{i} \mid v_{j}\right) \ldots(6)$

Substitusi persamaan ini akan menghasilkan :

$V_{M A P}=\arg _{v j \varepsilon v} \max P\left(v_{j}\right) \prod_{i} P\left(a_{i} \mid v_{j} \ldots\right.$ (7)

$P\left(\mathrm{v}_{\mathrm{j}}\right)$ dan probabilitas kata $\mathrm{w}_{\mathrm{k}}$ untuk setiap kategori $P\left(\mathrm{w}_{\mathrm{k}} \mid \mathrm{v}_{\mathrm{j}}\right)$ dihitung pada saat pelatihan.

$P\left(v_{j}\right)=\frac{\mid \text { docs } j \mid}{\mid \text { Contoh } \mid} \ldots$

$P\left(\mathrm{w}_{\mathrm{k}} \mid \mathrm{v}_{\mathrm{j}}\right)=\frac{n k+1}{n+\mid \text { kosakata } \mid} \ldots$

Di mana $\mid$ docs $j \mid$ adalah jumlah dokumen pada kategori $j$ dan |Contoh| adalah jumlah dokumen yang digunakan dalam pelatihan. Sedangkan $n_{k}$ adalah jumlah kemunculan kata $w_{k}$ pada kategori $v_{j}$ dan |kosakata| adalah jumlah kata yang unik (distinct) pada semua data pelatihan. Jumlah kata dalam tiap kelas dinyatakan sebagai $n$.

g. Kerangka pemikiran
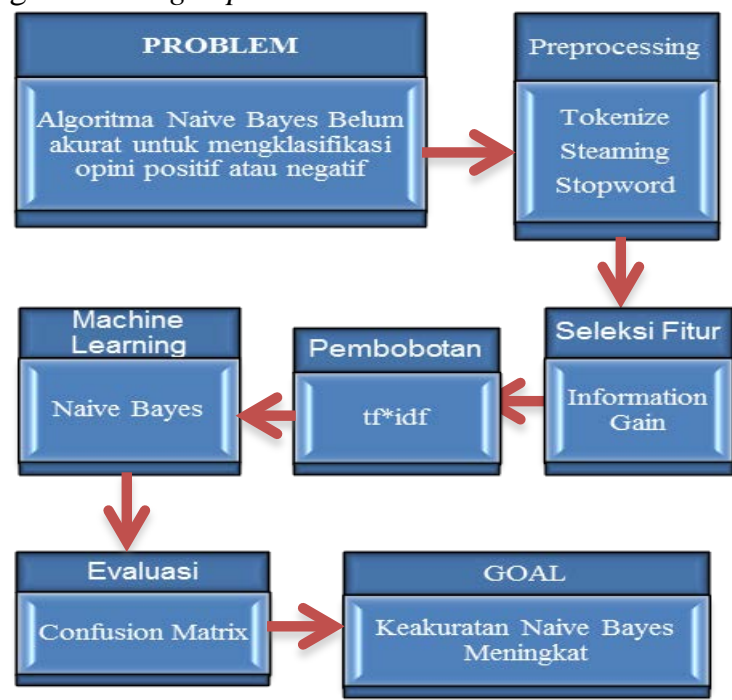

Gambar 1. Kerangka Pemikiran 


\section{METODE PENELITIAN}

Penelitian ini adalah diawali dengan mengambil dan mendownload data dari situs http://www.cs.cornell.edu/People/pabo/movie-

review-data/, Data tersebut awalnya dikumpulkan dari IMDb (Internet Movie Database) [2] [4]. Dataset yang digunakan dalam penelitian ini adalah dataset Movie Review sama seperti dataset yang digunakan oleh penelitian [4] [2] [6] [16] [15] data tersebut telah bersih dan siap digunakan sebagai corpus, dataset tersebut berjumlah 2000 file teks yang telah di berikan label yaitu 1000 positif dan 1000 negatif.

Setelah data didapatkan, dilakukan penggujian model dengan diawali langkah preprocessing yang terdiri dari tokenize adalah proses yang memecah aliran teks menjadi kata, frasa, simbol, atau unsur-unsur bermakna lain yang disebut token. Daftar token menjadi masukan untuk diproses lebih lanjut seperti parsing atau pertambangan teks. Tokenisasi adalah hal yang kompleks untuk program komputer karena beberapa karakter dapat ditemukan sebagai token delimiters. Delimiter adalah karakter spasi, tab dan baris baru “newline”, sedangkan karakter ()$<>$ ! ? “ kadangkala dijadikan delimiter namun kadang kala bukan tergantung pada lingkungannya [16].

Setelah melalui proses tokenize dan kalimat sudah dalam bentuk frasa, langkah selanjutnya adalah melalui tahapan Stopword yaitu menghapus daftar kata-kata yang tidak dipakai dalam pemroresan bahasa alami, dengan cara disaring sebelum pengolahan dokumen teks. Mereka umumnya dianggap sebagai 'kata-kata fungsional' yang tidak membawa makna seperti kata-kata

"affected, affecting, affects, after, afterwards, again, became, because, become, becomes, Becoming, been, before, became, because, become, becomes, becoming, been, before, dll.

Setelah melalui tahapan penyaringan kata yang di lakukan oleh stopword, langkah selanjutya adalah proses Steaming yang digunakan untuk mengurangi ukuran dari himpunan fitur awal dan untuk menghapus salah eja atau kata-kata dasar yang sama. Pada tahap ini dilakukan proses pengembalian berbagai bentukan kata ke dalam suatu representasi yang sama.

Setelah melalui tahapan preprocessing, langkah selanjutnya adalah menyeleksi feature yang akan dijadikan training dalam mesin pembelajaran, seleksi fitur yang digunakan dalam penelitian ini adalah Informationn Gain (IG) untuk bisa menghitung nilai dari IG nilai Entropy harus di ketahui terlebih dahulu, entropy bisa dikatakan sebagai bit untuk menyatakan suatu kelas. Semakin kecil nilai entropy maka semakin baik untuk digunakan dalam mengekstraksi suatu kelas. Tujuan dari gain adalah mengukur seberapa baik suatu atribut memisahkan training example ke dalam kelas target. Atribut dengan informasi tertinggi akan dipilih. Dengan tujuan untuk mendefinisikan gain. Setelah nilai gain dari term tiap-tiap dokumen training di ketahui, langkah selanjutnya adalah melakukan pembobotan untuk tiap-tiap term tersebut, pembobotan yang dilakukan dalam penelitian ini adalah pembobotan tf*idf. Prinsip kerja dari pembobotan yang digunakan merupakan sebuah perhitungan dari bagaimana term didistribusikan secara luas pada koleksi dokumen yang bersangkutan. Semakin sedikit dokumen yang mengandung term yang dimaksud, maka nilai idf semakin besar. Jika setiap dokumen dalam koleksi 
mengandung term yang bersangkutan, maka nilai dari idf dari term tersebut adalah nol. Hal ini menunjukkan bahwa sebuah term yang muncul pada setiap dokumen dalam koleksi tidak berguna untuk membedakan dokumen berdasarkan topik tertentu.

Penghitungan bobot dari term tertentu dalam sebuah dokumen dengan menggunakan tf*idf menunjukkan bahwa deskripsi terbaik dari dokumen adalah term yang banyak muncul dalam dokumen tersebut dan sangat sedikit muncul pada dokumen yang lain. Demikian juga sebuah term yang muncul dalam jumlah yang sedang dalam proporsi yang cukup dalam dokumen dikoleksi yang diberikan juga akan menjadi descriptor yang baik. Bobot terendah akan diberikan pada term yang muncul sangat jarang pada beberapa dokumen (low-frequency documents) dan term yang muncul pada hampir atau seluruh dokumen (high-frequency document).

Setelah nilai bobot dari tiap term pada seluruh dokumen yang telah terseleksi di ketahui, langkah selanjutnya adalah penerapan metode machine learning Nä̈ve bayes dengan tujuan untuk mengetahui klasifikasi atau sentiment dari data training apakah termasuk sentiment negatif atau sentiment positif.

\section{HASIL PENELITIAN}

Berdasarkan dari penerapan model yang digunakan dalam penelitian maka didapatkan keakuratan klasifikasi dari algoritma naïve bayes dan naïve bayes berbasis feature selection sebagai berikut:

\section{A. Nä̈ve Bayes}

Keakuratan klasifikasi dari naïve bayes untuk klasifikasi document movie review ditunjukan dengan Accuracy yang dihasilkan adalah sebesar $=95,15 \%$, Precision sebesar $=$ 96,40\% dan recal dihasilkan sebesar $=93,80 \%$ sebagaimana ditunjukkan pada gambar dibawah ini:

\begin{tabular}{|c|c|c|c|}
\hline \multicolumn{4}{|c|}{ (2) Talanaw O plotuen } \\
\hline \multicolumn{4}{|c|}{ 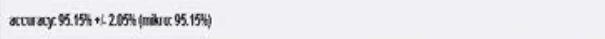 } \\
\hline & twensogit & troosotit & closs precision \\
\hline gror mestit & 950 & 62 & 99968 \\
\hline pres. postr & 35 & 988 & $8600 \%$ \\
\hline class real & $9550 \%$ & 938086 & \\
\hline \multicolumn{4}{|c|}{ 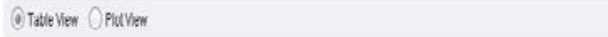 } \\
\hline \multicolumn{4}{|c|}{ 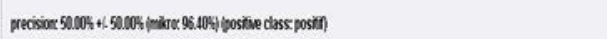 } \\
\hline & bueneydl & boy vosili & thass oretisin \\
\hline pod negetf & 965 & 62 & $8996 \%$ \\
\hline tred posill & 35 & 930 & $98,00 \%$ \\
\hline class racell & $9850 \%$ & $9300 \%$ & \\
\hline \multicolumn{4}{|c|}{ 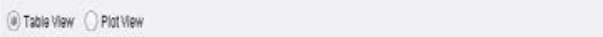 } \\
\hline \multicolumn{4}{|c|}{ 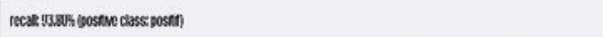 } \\
\hline & Tuengast & toaposert & cussspercision \\
\hline DFe. п9834 & 665 & 62 & $93.66 \%$ \\
\hline Oras . Doctit & s & 98 & 96.003 \\
\hline cless reeal & $9650 \%$ & $9300 \%$ & \\
\hline
\end{tabular}

Gambar 2. Nilai Precision dan Recall Klasifikasi Document Movie Review

B. Nä̈ve Bayes berbasis feature selection

Keakuratan klasifikasi dari naïve bayes berbasis feature selection untuk klasifikasi document movie review meningkat sebagaimana ditunjukan dengan accuracy sebesar $=95,70 \%$, Precision sebesar $=96,44 \%$ dan recal sebesar $=$ 94,90\%. Sebagaimana di tunjukkan dalam gambar di bawah ini:

\begin{tabular}{|c|c|c|c|}
\hline \multicolumn{4}{|c|}{ OTabe how OPollisw } \\
\hline \multicolumn{4}{|c|}{ 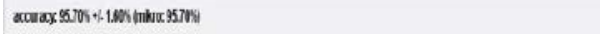 } \\
\hline & twe ragatt & naposts & Cass preatom \\
\hline pat tegatt & $66 \%$ & 51 & 81933 \\
\hline pet pouff & 35 & 3.4 & 9543 \\
\hline class ral & $9650 x$ & $40 \%$ & \\
\hline \multicolumn{4}{|c|}{ OTale liew Opthier } \\
\hline \multicolumn{4}{|c|}{ 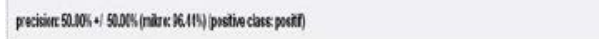 } \\
\hline & Tunagat & TRA:CSUI & casspetsison \\
\hline pred ringall & 965 & 51 & 9485\% \\
\hline pred postif & s & 343 & $954 \%$ \\
\hline dossneal & s:t06 & 49936 & \\
\hline \multicolumn{4}{|c|}{ OTatlen Opltiley } \\
\hline \multicolumn{4}{|c|}{ 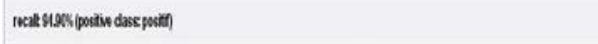 } \\
\hline & re *gat & tueposts & stess precien \\
\hline ped rogyill & 35 & 51 & 34935 \\
\hline pred wast & $x$ & M! & 3645 \\
\hline dastreal & $250 \%$ & $900 \%$ & \\
\hline
\end{tabular}

Gambar 3. Nilai Precision dan Recall feature selection Untuk Klasifikasi Document Movie Review 
Gambar 3 diatas menunjukkan analisa evaluasi hasil Naïve Bayes dan Fitur Selection dengan selisih nilai akurasi sebesar 0,55 , akurasi yang dihasilkan dalam penelitian ini dapat melampaui akurasi dari penelitian yang di jadikan baseline yaitu penelitian somayajulu [7] akurasi tertinggi sebesar 94,85\%. dan penelitian [14] dengan akurasi tertinggi sebesar 85,60\%.

Dalam uji coba yang dilakukan dengan accuracy, Precision dan Recal yang di hasilkan antara naïve bayes dan naïve bayes berbasis selection feature berbeda, perbedaan tersebut terutama terdapat dalam jumlah total dokumen positif benar diklasifikasikan positif dan dokumen negatif benar diklasifikasikan negatif.

Seperti pada pemodelan naïve bayes, jumlah total dokumen uji adalah sebesar 2000 dokumen yang terdiri dari 1000 positif dan 1000 negatif. Tetapi di dalam model naïve bayes, dokumen negatif yang benar diklasifikasikan negatif adalah sebesar 965 dokumen, dan dokumen negative yang diklasifikasikan ke positif sebesar 35 dokumen. Dokumen positif yang benar dikalasifikasikan ke positif sebesar 938 dokumen dan dokumen positif yang masuk kekategori negatif sebesar 62 dokumen.

Setelah pemodelan naïve bayes di beri selection feature, terjadi sedikit perubahan dalam klasifikasi seperti yang terjadi pada dokumen kategori positif sedangkan dokumen yang berkategori negatif tidak terjadi perubahan dalam proses klasifikasi masih tetap seperti pemodelan naïve bayes. Peningkatan tersebut terjadi pada Dokumen positif yang benar dikalasifikasikan ke positif sebesar 949 dokumen dan dokumen positif yang masuk kekategori negatif sebesar 51 dokumen.

\section{KESIMPULAN DAN SARAN}

Berdasarkan penelitian yang dilakukan dapat disimpulkan bahwa :

Accuracy yang dihasilkan dari penelitian ini dapat melampaui accuracy dari penelitian yang dijadikan base line yaitu penelitian [14] [7] menggunakan metode NB dan comparasi beberapa fitur seleksi, accuracy terbesar didapatkan oleh CMD sebesar 85,60\% dan [7] sebesar 94,85\%.

Accuracy tersebut dilampaui tanpa memberi seleksi fitur terhadap algoritma Naïve Bayes, naïve bayes hanya diberikan pembobotan tf*idf, accuracy yang dihasilkan tanpa memberikan seleksi fitur adalah sebesar 95,15\%. Accuracy yang dihasilakan setelah memberikan seleksi fitur adalah sebesar 95,70\%, mengingkat sebesar 0,9\%. Peningkatan accuracy dalam pengklasifikasian dokumen dengan penambahan seleksi fitur, peningkatan accuracy yang dihasilakan memang tidak terlalu tinggi dari naïve bayes tanpa seleksi fitur.

\section{REFERENSI}

[1] George Stylios et al., "Public Opinion Mining for Governmental Decisions," Electronic Journal of eGovernment, vol. 8, no. 2, pp. 202-213, 2010.

[2] Pimwadee Chaovalit and Lina Zhou, "Movie Review Mining: a Comparison between Supervised and Unsupervised Classification Approaches," IEEE, pp. 1-9, 2005.

[3] Bo Pang and Lillian Lee, "Opinion mining and sentiment analysis," Foundations and Trends in Information Retrieval, vol. 2, no. 1-2, pp. 1-135, 2008.

[4] Bo Pang, Lillian Lee, and Shivakumar Vaithyanathan, "Thumbs up? Sentiment Classification using Machine Learning Tehniques," Proceedings of the Conference on Empirical Methods in Natural Language Processing (EMNLP), pp. 79-86, July 2002.

[5] Ahmed Abbasi, Hsinchun Chen, and Arab Salem , "Sentiment analysis in multiple languages : Feature selection for opinion clasification in web forums," ACM Transactions on Information Systems, vol. 26, no. 3, pp. 1-34, 2008.

[6] Tim O Keefe and Irena Koprinska, "Feature Selection and Weighting Methods in Sentiment Analysis," Proceedings of the 14th Australasian Document Computing Symposium, pp. 1-8, Desember 2009. 
[7] Somayajulu, Siva RamaKhrisnha Reddy, and Ajay Dani, "Classification of Movie Reviews Using Complemented Naive Bayesian Classifier," International Journal of Intelligent Computing Research (IJICR), vol. 1, pp. 162-167, 2010.

[8] Long Sheng Chen and Chia Wei Chang, "A New Term Weighting Method by Introducing Class Information for Sentiment Classification of Textual Data," Proceeding of International MultiConference of engineers and Computer Scientists, IMECS, vol. 1, pp. 1-4, March 2011.

[9] Colas Fabrice and Brazdil Pavel, "Comparison of SVM and Some Older Classification Algorithms in Text Classification Tasks," Artificial Intelligence in Theory and Practice, vol. 217, no. 1, pp. 169-178, 2006.

[10] Vidhya K A and G Aghila , "A Survey of Naïve Bayes Machine Learning approach in Text Document Classification," International Journal of Computer Science and Information Security,IJCSIS, vol. 7, no. 2, pp. 206-211, 2010.

[11] Erik Boiy, Pieter Hens, Koen Deschacht, and Marie Francine Moens, "Automatic Sentiment Analysis in Online Text," Proceedings ELPUB2007 Conference on Electronic Publishing, pp. 349-360, June 2007.

[12] Wen Zhang, Taketoshi Yoshida, and Xijin Tang, "A Study with Multi-Word Features in Text Classification," Proceedings of the 51st Annual Meeting of the ISSS, pp. 1-8, 2007.

[13] Yelena Mejova, Topic Tracking \& Sentiment Analysis in Twitter, University of Iowa, 2011.

[14] Jingnian Chen, Houkuan Huang, Shengfeng Tian, and Youli Qu, "Feature selection for text classification with Naïve Bayes," in Expert Systems with Applications. Beijing, China: Elsevier Ltd, 2009, pp. 5432-5435.

[15] Bruno Ohana and Brendan Tierney, "Supervised Learning Methods for Sentiment Classification with RapidMiner," RapidMiner Community Meeting And Conference, RCOMM, pp. 1-8, June 2011.

[16] Rawia Awadallah, Maya Ramanath, and Gerhard Weikum, "Harmony and Dissonance: Organizing the People's Voices on Political Controversies," Proceedings of The Fifth ACM International Conference On Web Search And Data Mining, ACM, pp. 523-532, February 2012.

[17] Louise Francis and Matt Flynn, Text Mining Handbook: Spring, 2010. 